\section{Role playing vs laboratory deception: A comparison of methods in the study of compromising behavior*}

\author{
RICHARD M. ROZELLE, University of Houston, Houston, Tex. 77004 \\ and
}

DANIEL DRUCKMAN, Institute for Juvenile Research, Chicago, IIl. 60612

A comparison of role-playing vs laboratory deception methods was conducted in the context of varyirg pressures to compromise one's religious beliefs in an anticipated negotiation session. Results revealed a subtle interaction effect produced in the laboratory deception condition which was not obtained for the role-playing condition. Other results are discussed, and caution is advised in interchangeably employing both methods.

A growing concern in psychological research has involved the use of deception in experiments and the major substitute suggested for it: role playing (Kelman, 1967; Vinacke, 1954). Among the studies which have explored this possibility are experiments conducted by Bem (1967, 1968; Bem \& McConnell, 1970), Darroch \& Steiner (1970), Greenberg (1967), Horowitz \& Rothschild (1970), and Willis \& Willis (1970). Although these studies involved a wide range of specific theoretical inputs and a diversity of topics as well as different approaches to comparing the deception vs role-playing models, it may be concluded that there has been a marked degree of success in terms of the overall consistency of the results generated among the two models. However, the Darroch and Steiner and the Willis and Willis studies have pointed out certain inconsistencies between the two models that warrant further investigation. Darroch and Steiner observed that role-playing $\mathrm{Ss}$ will not yield results identical to those of the actual experimental Ss when "subjects are asked to role-play someone other than themselves whose implicit theory differs from their own, when the experiment involves highly novel circumstances which have not been assimilated into subjects' implicit theories, or when the laboratory situation is so complex that its important features cannot readily be discerned and communicated to role-playing subjects [1970, p. 310$]$." Moreover, in a more direct comparison involving the presence or absence of deception, Willis and Willis found that in addition to the replicated main effect exhibited in both the laboratory

\footnotetext{
*This study was partially supported by General Support Grant FR-05666-02 awarded to the Institute for Juvenile Research by the National Institutes of Health. The authors wish to thank Harry Hallows, Jeffrey Leeds, Gregory King, George Dempsey, Blake Frank, and Sol Satin for their help in data collection and clerical assistance.
}

deception and role-pláying conditions, a subtle but significant interaction effect was observed for the deception but not for the role-playing Ss.

The present study involved the effects of representation and type of issue upon willingness to take a counterattitudinal position (or, compromise one's own position) on a religious belief in an upcoming negotiation session. However, for the purposes of this report, emphasis will be placed on the general results comparing the two methods, with only brief mention of the specific topics investigated. The major prediction based upon the previous studies cited is that data obtained from the laboratory deception method should reveal more subtle interaction effects not evidenced from data produced from the role-playing technique. For a more detailed discussion of the topic-related results and the variables themselves, see Druckman and Rozelle. ${ }^{1}$

\section{DESIGN AND SUBJECTS}

The Ss were 191 students enrolled in the introductory psychology courses at the University of Houston. All of the Ss volunteered to serve in the experiment and received extra class credit for doing so.

The experimental conditions were arranged in a 2 by 2 by 2 factorial design, each variable having two levels. The conditions were: (1) centrality-peripherality of the religious issue to be discussed in the upcoming debate; ${ }^{2}$ (2) representation in which the $S$ was to either represent only himself (individual) or speak for a group of constituents (group) in the debate; (3) method, in which the above variables were manipulated in a laboratory-deception condition or in a role-playing condition.

The measure of willingness-tocompromise was created by instructing the $\mathrm{S}$ to argue for the position opposite to his actual position on the designated issue. The $S$ was also informed that his opponent in the debate would be arguing for the opposite position (or the Ss' actual positions). He was then asked whether or not he could actually carry this assignment out or, if he could not, how far would he be willing to go (i.e., compromise his original position) in order to defend the assigned position (either for himself or as a representative of his "group").
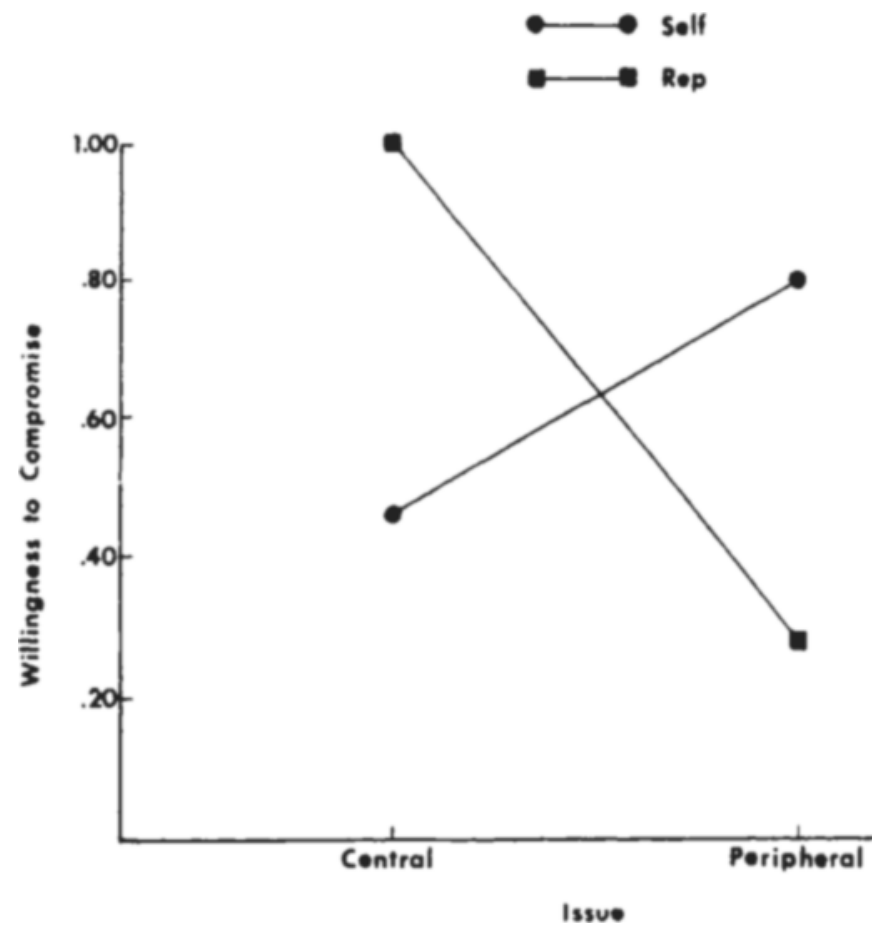

Fig. 1. Degree of compromise for the laboratory deception conditions. 
However. he was informed that he would be forfeiting some "competitive advantage" if he decided to take a position other than the suggested one. Thus, the degree to which the $S$ conformed to the experimental instructions was directly related to willingness to compromise his personal belief on a particular issue.

\section{LABORATORY VS}

\section{ROLE-PLAYING PROCEDURE}

First, it is important to point out that the term "role playing" has been used to refer to two major types of conditions: those in which the $S$ actually acts out an assigned role and those in which the $S$ simply relates how he would perform "if" he were an actor in the experiment. The present study employs the role-playing condition only in the latter case, with the $S$ asked to give estimates of his behavior as "if" he were actually performing in a described role and situation.

There were three major differences between the laboratory and role-playing replications. In the laboratory condition, the following deceptions were used: (1) each $S$ was led to believe that he and an opponent would take part in a debate immediately following the predebate questioning period; (2) each $S$, in the representation condition, was led to believe that he was chosen as the representative or spokesman for his group and that the other three group members present for the session were to be teammates; (3) the Ss were told that the opponent (either individual or group representative) was waiting in another room and was preparing to defend his assigned position in the upcoming debate. In the role-playing replications, Ss were presented with a scenario that described the laboratory experiment as it was actually run. They, of course, knew that they would not actually debate and that an opponent was not "waiting in another room preparing his assigned position..." They were told to act "as if" they were going to debate the position that they selected. In the laboratory condition, $S s$ in the individual variation were run individually, while those in the group representation variation were run in groups of four. In both conditions, Ss were assigned randomly to issue and representation conditions.

In addition, for both the role-playing and laboratory conditions, the initial attitudinal position on the relevant issue for each $S$ was categorized as being either "extreme" or "moderate" in terms of degree of agreement or disagreement with the issue statement. This variable was included in the analysis of variance.

$$
\text { RESLLTS }
$$

Due to a proportional relationship

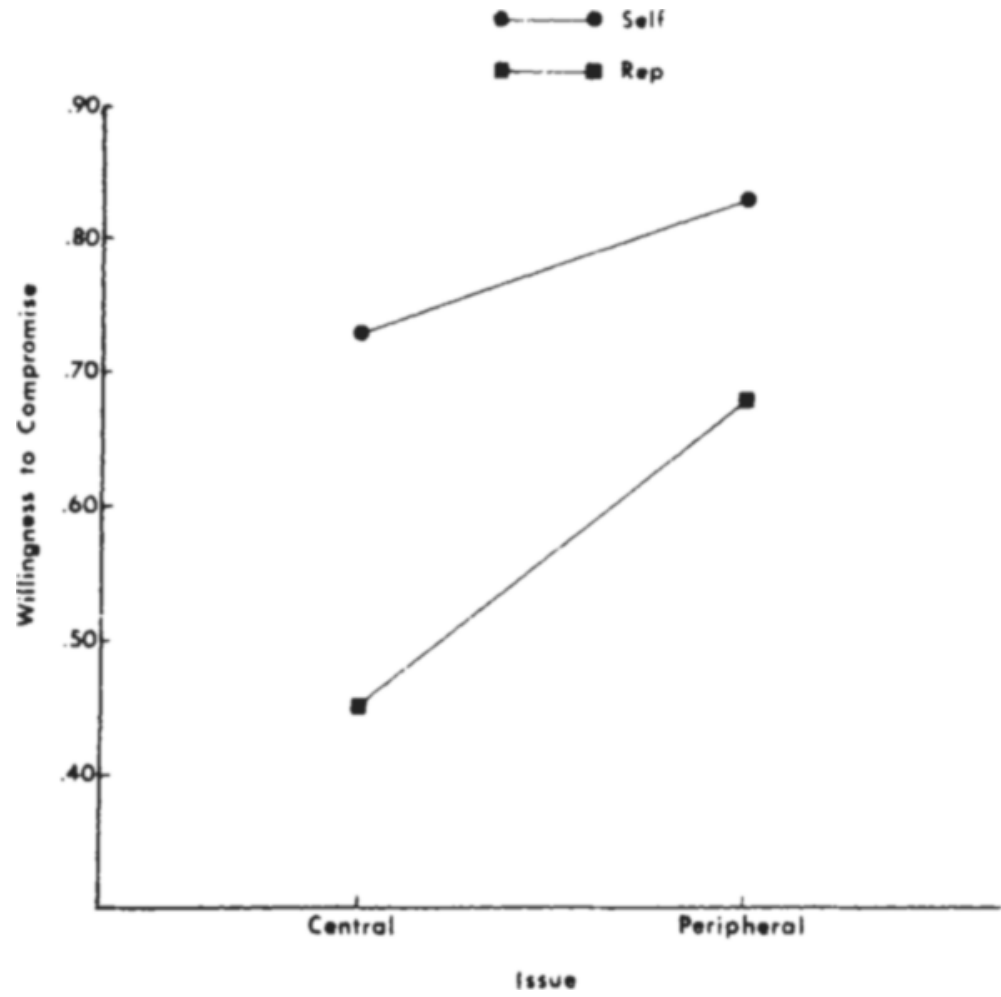

Fig. 2. Degree of compromise for the role-playing conditions.

among the means and variances for the treatment conditions, a square-root transformation was performed on the willingness-to-compromise measure. ${ }^{3}$ The results of a four-way analysis of variance indicated a significant four-way interaction effect of Method by Representation by Issue by Initial Attitudinal Position ( $F=7.36$, $\mathrm{df}=1 / 175, \mathrm{p}<.01)$. A main effect for initial position was also obtained $(F=5.09$, df $=1 / 175, p<.02)$. This indicated that for both the role-playing and laboratory-deception conditions, those $\mathrm{Ss}$ with extreme initial positions were not willing to move as far toward the suggested position as those with moderate initial positions across all issue and representation conditions.

The data were reanalyzed for initial position, and no significant main or interaction effects were obtained for moderates. However, a number of significant effects were obtained when the data were analyzed for extremists $(\mathrm{N}=41$ for the laboratory-deception condition; $N=51$ for the role-playing condition). A significant three-way interaction was obtained between method, representation, and issue $(F=12.68, \mathrm{df}=1 / 85, \mathrm{p}<.001)$. This interaction was broken down by performing separate two-way analyses for each method. The results of these analyses are presented in Figs. 1 and 2. A significant Representation by Issue interaction was obtained for the laboratory-deception method
( $F=16.95, \mathrm{df}=1 / 37, \mathrm{p}<.001$ ) that was not present for the role-playing method. Representatives compromised more than individuals for the central issue, while the reverse was observed (viz, individuals compromised more than did representatives) on the peripheral issue. A borderline issue main effect was also obtained for the laboratory-deception method $(F=3.84, \cdot d f=1 / 37, p<.06)$, which indicated more compromise on the central issue than on the peripheral issue. A significant main effect for representation was obtained for the role-playing method ( $F=5.72$, $\mathrm{df}=1 / 48, \quad \mathrm{p}<.02)$. Ss who represented themselves compromised more than did those who represented groups on both the central and peripheral issues (see Fig. 2). Also, the issue main effect reached borderline significance $(\mathrm{F}=2.89, \quad \mathrm{df}=1 / 48$, $\mathrm{p}<.10)$.

\section{DISCUSSION}

Although several highly significant effects were obtained, only moderate similarity was observed among these effects between the experimental deception and role-playing methods. The individual condition displayed a similar trend between the two methods in that more compromising was evidenced for the peripheral than for the central issue. This general trend for the individual condition was obtained for both moderate and extreme scorers but produced significant effects only when 
extremists were analyzed. However, for the group representation condition, the trend for compromising across issues for the experimental deception method was opposite to that obtained for role playing.

Of most interest is the interaction effect between representation and issue which was obtained only in the experimental deception condition. This represents a striking similarity to those findings reported by Willis \& Willis (1970), where a "subtle", interaction effect was obtained only for the laboratory deception condition. In the present study, the representation effect entered into either significant main or interaction effects for both methods. While a more obvious main effect was obtained for representation in the role-playing condition, this variable was only significant in a more subtle interaction with issue for the laboratory deception method. Representatives compromised more than did nonrepresentatives on the central issue for the deception data, while the reverse occurred for the role-playing data. Nonrepresentatives compromised more than representatives on the peripheral issue for both methods. It must be pointed out, however, that unlike Willis and Willis, the present study did not obtain identical main effects across the two methods. Representation was significant only for the role-playing technique, whereas issue was of borderline significance only for the laboratory deception method.

From a more specific viewpoint, the present study could be classified as representing the "forewarning" rather than the "prebriefing" variant of role playing (Willis \& Willis, 1970) in that the $\mathrm{S}$ was only asked to assume the role of a naive $S$ with no further elaborated details describing experimental manipulations having been presented. Although no direct comparison could have been made between the two types of role-playing variants, it could be stated that due to the disparity of results between the "forewarning" variant and the laboratory deception conditions, the present study does not lend support to the general finding of Horowitz \& Rothschild (1970), where it was discovered that the forewarning variant (as opposed to that of prebriefing) more accurately replicated results obtained from the laboratory deception method. A more direct comparison of various levels of forewarning and prebriefing will be examined in future research to be conducted by the present authors.

An important feature of the present study was that the analysis of variance permitted a direct determination of the amount of variance accounted for by method (laboratory deception vs role playing) relative to the other variables. The results obtained were not entirely consistent with those of Darroch \& Steiner (1970), who used a similar data analysis. For the present study, significant method variance occurred only in interaction effects, whereas Darroch and Steiner obtained only main effects for this variable. Due to the lack of similarity concerning specific aspects of the two studies, it is felt that detailed explanations for these discrepant results are unwarranted at this time.

It is obvious that quite different conclusions would have been made had only one of the methods been utilized. With increasingly refined techniques in social psychological experimentation, interaction effects assume greater explanatory importance. The conditions under which these effects can be produced and replicated needs further study. In any event, present data would seem to indicate that caution be advised in assuming that role-playing and laboratory deception techniques may be employed interchangeably.

$$
\text { REFERENCES }
$$

BEM, D. J. Self-perception: An alternative interpretation of cognitive dissonance phenomena. Psychological Review, 1967, 74, 183-200.

BEM, D. J. The epistomological status of interpersonal simulations: A reply to Jones, Linder, Kiesler, Zanna \& Brehm. Journal of Experimental Social Psychology, 1968, 4, 270-274.

BEM, D. J., \& MCCONNELL, H. K. Testing the self-perception explanation of dissonance phenomena: On the science of premanipulation attitudes. Journal of Personality \& Social Psychology, 1970, 14, 23-31.

CLYDE, J., CRAMER, E. M., \& SHERIN, R. J, Multivariate statistical programs. Biometric Laboratories, University of Miami, Coral Gables, Florida, 1966.

DARROCH, R. K., \& STEINER, I. D. Role-playing: An alternative to laboratory research? Journal of Personality, 1970, 38, 302-311.

HOROWITZ, I. A., \& ROTHSCHILD, B. $H$. Conformity as a function of deception and role playing. Journal of Personality \& Social Psy chology, 1970, 14, 224-226.

GREENBERG, M. S. Role playing: An altemative to deception? Journal of Personality \& Social Psychology, 1967, 7, $152-157$.

KELMAN, H C Human use of human subjects: The problem of deception in social psychological experiments. Psy chological Bulletin, 1967, 67, 1-11.

VINACKE、W. E. Deceiving experimental subjects. American Psychologist, 1954, 9, 155.

WILLIS, R. H., \& WILLIS, Y. A. Role playing versus deception: An experimental comparison. Journal of Personality \& Social Psychology, 1970, 16, 472-477.

\section{NOTES}

1. Druckman, D., \& Rozelle, R. M Performance evaluation as a determinant of willingness to compromise beliefs. Submitted for publication.

2. On the basis of previous research, one central issue ("Jesus was born of a virgin") and one peripheral issue ("Natural techniques, abstinence or rhythm, are the only acceptable methods of birth control") was selected for the present investigation.

3. In order to take account of unequal cell sizes, an unweighted means analysis of variance was performed using the computer program MANOVA (see Clyde, Cramer, \& Sherin, 1966). 